\title{
Leaders
}

\section{Recent advances in the study of tumour invasion and metastasis}

\author{
D Tarin, Y Matsumura
}

\section{Introduction}

The application of recently developed research techniques to the study of tumour invasion and metastasis has uncovered new and surprising information which has focused increasing clinical and scientific interest on this aspect of neoplasia. The magnitude of the effect of this problem on health is revealed by reference to the annual mortality statistics published by the Registrar General of England and Wales. These show that about one in three of the population die of the consequences of metastatic cancer, or are found to harbour asymptomatic metastatic tumour deposits at necropsy. Research on this subject is therefore directed at controlling a major, clinically important phenomenon. A selection of recent advances which offer new opportunities for early diagnosis or treatment of this aspect of malignant disease are surveyed in this brief overview.

Nuffield Department of Pathology,

University of Oxford, John Radcliffe

Hospital, Headington

Oxford OX3 9DU

D Tarin

Y Matsumura

Accepted for publication 7 October 1993

\section{Clinical and experimental background}

The invasive and metastatic activity of malignant tumours has, until now, seemed to be an almost insuperable problem, best illustrated by a clinical example. The patient whose leg is shown in fig 1A had initially presented two years earlier with a small melanoma. This was treated by wide local excision and grafting of skin from the back of her torso. Subsequently an advancing wave of dermal metastases (fig 1B) gradually ascended her leg. Metastatic tumour then colonised and replaced her inguinal lymph nodes and went on progressively to take over the para-aortic group. Finally, haematogenous metastasis began, evidenced by the presence of pigmented tumour deposits in the brain at necropsy (fig 1C). Death, in this case, was due to an unrelated condition, but is more often due in disseminated malignancy, to organ failure following replacement by tumour (fig 1D). As the metastases in this patient only appeared after excision of the small primary tumour, they must have already been disseminated. Equally, the eventual appearance of metastatic deposits in the grafted skin (fig 1A), donated from a remote site which never developed dermal secondaries, illustrates that metastases themselves act as new foci for further dissemination, resulting in a geometric increase in the impact of the tumour on the host.

Clinical experience, therefore, teaches that malignancy is often already systemic from very early in the life history of a neoplasm and that patients may harbour many covert seedling tumours at the time of first presentation with symptomatic lumps. Diagnostic and therapeutic policy need to be predicated on this understanding. As the treatment of established metastases is presently rather crude, toxic, and limited in success, the clinical man-
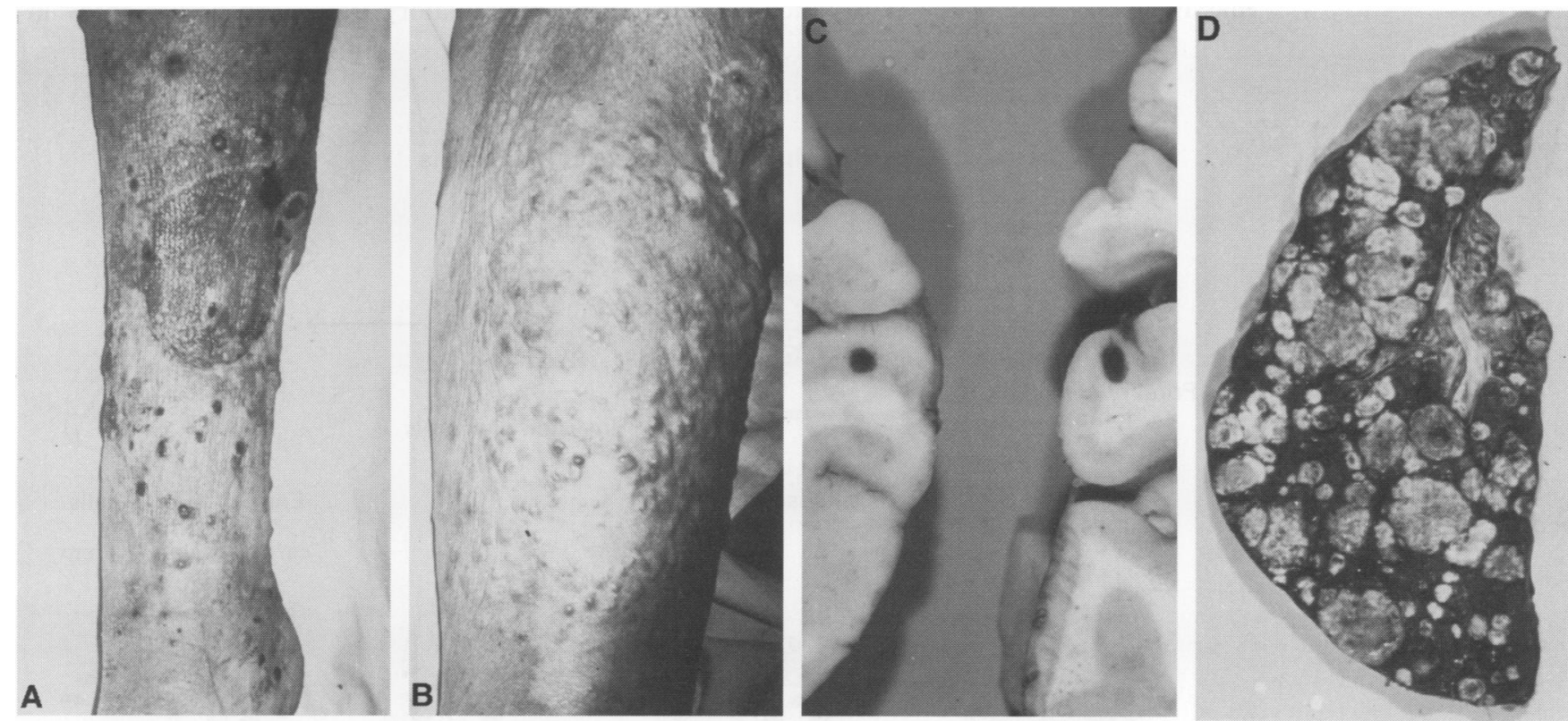

Figure 1A Pigmented metastases in the leg of a patient with malignant melanoma. The site of resection of the primary tumour can be seen and deposits are even present in the skin graft covering the deficit. $1 B$ Thigh of the same patient showing numerous cutaneous metastases, some of which are pigmented. A pale scar can be seen in the groin at the site of previous resection of deposits in the inguinal nodes. $1 C$ Portions of two slices of the brain of this patient. Pigmented metastases can be seen in the grey matter of the cerebral cortex. $1 D$ Unpigmented metastases in liver of another patient with malignant melanoma. 
agement of malignancy will benefit from efforts to improve early diagnosis of cancer and to impede tumour dissemination. New advances which contribute in some way to these objectives may be grouped as follows:

(1) The earlier a tumour can be detected, preferably non-invasively, the better because surgery and radiotherapy are now very effective for the treatment of neoplasms that are still localised. New strategies described below, of searching for tumour related abnormal gene activity with recently developed amplification methods to increase sensitivity, are therefore being developed to facilitate early detection.

(2) Other work in progress offers the prospect of methods for the evaluation of the metastatic potential of a tumour biopsy or needle aspirate, to assist choice of treatment.

(3) It has recently been demonstrated that tumour cells entering the circulation in patients with cancer do not necessarily form metastases even when they do so in large numbers. This has implications for judging prognosis and treatment and for monitoring disease recurrence.

(4) Another group of results pertain to the aim of blocking tumour invasion and metastasis in patients who could already have some deposits. Such endeavour is worthwhile even when some metastases are known to be present, in the service of trying to gain the patient some advantage from reduction in the geometric advance of the disease.

Current understanding of the spread of cancer in the human body ${ }^{1}$ is based on a good deal of previous research which has established that firstly it is a stepwise phenomenon (fig 2) capable of being undertaken by only a subpopulation of cells within the heterogeneous masses of cells in a tumour, ${ }^{2} \mathrm{sec}-$ ondly that it is highly selective and results in massive losses among the cells which set out on the venture ${ }^{3-5}$ and thirdly that it is stably propagated over many generations among the cells which survive to form secondary tumour deposits. ${ }^{2}$ Hence it is likely to be genetically programmed.$^{67}$ It is also known from many clinicopathological studies that metastasis can occur via several anatomical pathways ${ }^{68}$ and that the distribution of tumour deposits tends to occur in non-random, organ selective patterns according to the site and histogenetic origin of the primary tumour. It seems, therefore, to be subject to modulation by local environmental factors in the sites of tumour cell arrest, an interpretation also favoured by recent experimental data..$^{9-12}$ The advances to be discussed are consistent with, and support, this earlier framework of understanding.

\section{Early tumour diagnosis as a practical} means of controlling metastatic sequelae Recent studies have provided evidence that the activity of the CD44 gene is severely deranged in many types of tumours. ${ }^{13-16}$ This gene normally codes for a family of heavily glycosylated cell surface proteins, the multiple isoforms of which exercise many important cellular functions. ${ }^{18}$ In cancer there is chaotic overproduction of many unusual mRNA transcripts, relative to the picture seen in corresponding normal or non-neoplastic tissues. As the disorder is present in early tumours (Matsumura et al, unpublished observations) and can be identified in very small samples using amplification techniques, it seems a promising candidate to study as a possible marker for early diagnosis and for monitoring patients for local and distant recurrent disease. ${ }^{13}$

The first observation that there is gross overexpression of numerous splice variants from this gene in human tumour tissue was serendipitously made in the course of studying metastatic cells to test the hypothesis ${ }^{19}$ that such cells are inappropriately activating genetic programmes for white cell (especially lymphocyte) recirculatory traffic. An earlier study in
Figure 2 The multistep process of metastasis.
The Multistep Process of Metastasis

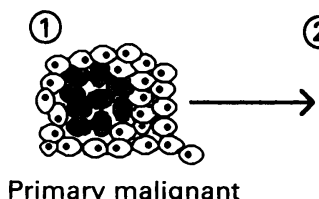

Primary malignant tumour

(2) (3)

$\rightarrow$

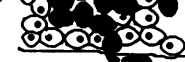

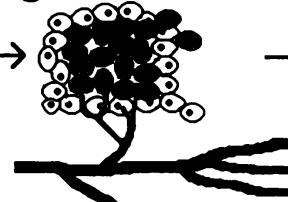

Invasion of vessels

Multiplication, invasion and vascularisation

(5)

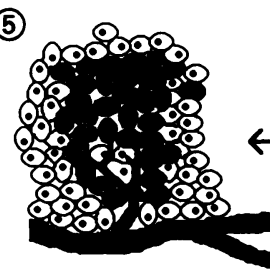

(6)

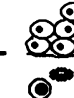
Extravasation of tumour cells
in a downstream organ
Arrest of tumour cells in downstream organs 
A

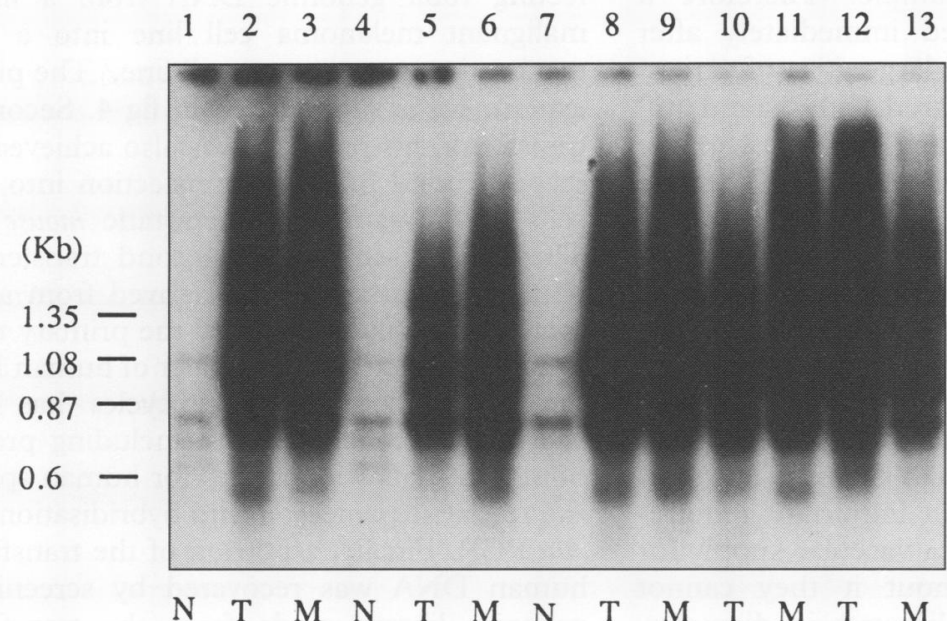

B $\begin{array}{lllllll}14 & 15 & 16 & 17 & 18 & 19 & 20\end{array}$

C

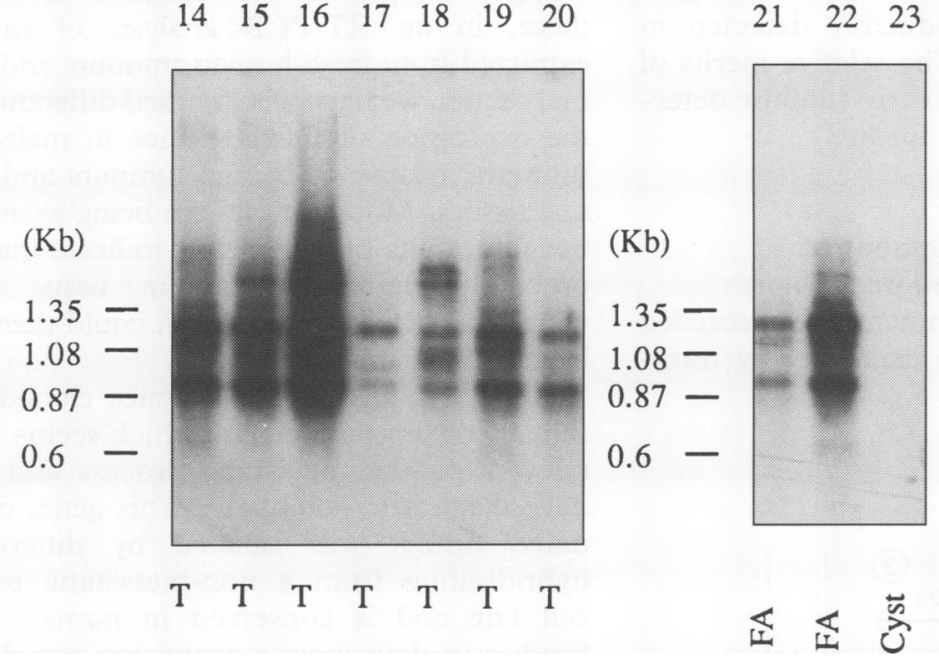

Figure 3 Deranged CD44 expression in breast cancer. (A) Malignant primary breast carcinomas with metastases. Tracks 1,2 , and 3 patient $B 1 ; 4,5$, and $6 B 2 ; 7,8$, and 9 $B 3 ; 10$ and 11 B4; 12 and 13 B5. Compared with normal breast tissue, primary breast carcinomas overexpress several splice variants. (B) Breast carcinomas from patients with no clinical evidence of metastasis: all overexpress several variants but show fewer bands and, in general, the intensity is less. (C) Fibroadenomas (FA) and fibrocystic disease (Cyst) of the breast. Notation: $N=$ normal; $T=$ tumour; $M=$ metastasis.

this laboratory had provided evidence that the integrin VLA-4, commonly seen on trafficking lymphocytes, is upregulated on metastatic but not on non-metastatic tumour cells. ${ }^{20}$ It was therefore decided to examine CD44 expression in such cell lines, because it had been identified as a lymphocyte homing molecule, aiding these white cells to traffic through lymph nodes. The results with human cell lines were disappointing, there being no clear correlation with metastatic capability. However, a report from another laboratory, of differential expression of a particular small portion of the gene in metastatic and non-metastatic cell lines derived from a rat pancreatic adenocarcinoma ${ }^{21}$ indicated that it may play a part in this process in some circumstances. We therefore examined CD44 gene activity in fresh human tumour tissue and metastases with more sensitive techniques. ${ }^{13}$ The resulting findings were dramatic (fig 3). They were obtained with the technique of reverse transcription, followed by polymerase chain reaction amplification (RTPCR), and showed very disorderly expression of this gene in tumour samples. It can be seen from this picture that the differences between tumour tissue and normal tissue were obvious and increased in severity with progression of malignancy to metastatic behaviour. Our subsequent studies have shown that such abnormalities are present in a wide variety of common cancers (table), but not in corresponding normal tissues. By refining the technique we have also been able to show that with this method even small numbers of tumour cells can be detected in urine obtained noninvasively, by natural micturition, from a very high proportion of patients with bladder cancer. ${ }^{18}$ The implications for non-invasive investigation of patients for the possible presence of tumours in accessible sites are obvious and are being explored. So far the results are scientifically very encouraging and interesting, but the numbers of cases with malignant disease and of controls with non-neoplastic conditions needs to be expanded greatly, with inclusion of double blind protocols, before it will be possible to decide whether the method can be dependably used in clinical practice. Also, the work to date has shown that disturbed activity of the CD44 gene is not exclusively associated with metastasis, but is seen in many types of tumours and seems to increase progressively with malignancy. The exact reasons for such abnormal activity of this gene and of its association with neoplasia await further investigation.

Other laboratories have explored the possibility of detecting $\mathrm{p} 53^{22}$ or $\mathrm{ras}^{23}$ mutations with PCR based techniques, to diagnose the presence of cancer cells in the urine of patients with bladder cancer, but the methods needed for such DNA based tests are more complicated and their usefulness for general cancer detection is limited by the fact that only a proportion of patients with the condition have the mutation in their tumour cells. Although an improvement in the methods of extracting RNA from clinical samples is greatly needed, RNA based diagnosis promises to be simpler and more practical for the investigation of a given individual who may currently have disease. DNA based techniques are probably more suited to the analysis of familial and aetiological associations. A cautionary note needs to be made: mRNA is notoriously susceptible to degradation by any

Table Derangement of CD44 expression in tumours

\begin{tabular}{lll}
\hline Type of tissue & $\begin{array}{l}\text { Number of } \\
\text { patients/ } \\
\text { volunteers }\end{array}$ & $\begin{array}{l}\text { Number } \\
\text { showing } \\
\text { increased } \\
\text { splice variants }\end{array}$ \\
\hline Neoplastic & 47 & 46 \\
Breast cancer & 21 & 21 \\
Colon cancer & 13 & 13 \\
Bladder cancer & 6 & 6 \\
Stomach cancer & 1 & 1 \\
Thyroid cancer & 1 & 1 \\
Fibroadenoma & 2 & 2 \\
Prostate cancer & 3 & 2 \\
Non-neoplastic & 39 & 0 \\
Normal breast & 9 & 0 \\
Cystic disease of breast & 1 & 0 \\
Normal colon & 9 & 0 \\
Crohn's disease & 1 & 0 \\
Ulcerative colitis & 1 & 0 \\
Appendicitis & 1 & 0 \\
Normal bladder & 4 & 0 \\
Peripheral blood leucocytes & 10 & 0 \\
Bone marrow & 3 & 0 \\
\hline
\end{tabular}


ribonucleases in the sample. Therefore if extraction is not started immediately after thawing a specimen, the larger size of variant CD44 molecules, compared with "standard" ones, means that they are more susceptible and might not be detected, giving a false negative result.

A completely different approach is being explored by Folkman and colleagues for the detection of bladder cancer using urine samples. ${ }^{24}$ This entails detection of tumour angiogenesis factor by radioimmunoassay. The production of angiogenesis factors has been demonstrated by Folkman's group in many previous studies to be an important requirement for recruitment of a vascular supply for growing tumours. Without it they cannot grow beyond a few millimetres in diameter. The idea is therefore very original and interesting, but at present there is insufficient information to judge whether, in the absence of amplification small quantities of such signal molecules can be reproducibly detected in large volumes of fluid. The relative merits of these novel methods for early tumour detection need to be evaluated further.

New methods for assessment of metastatic potential and prognosis

In a recent series of experiments we succeeded in transferring metastatic capability by trans-

Transfection of Metastasis
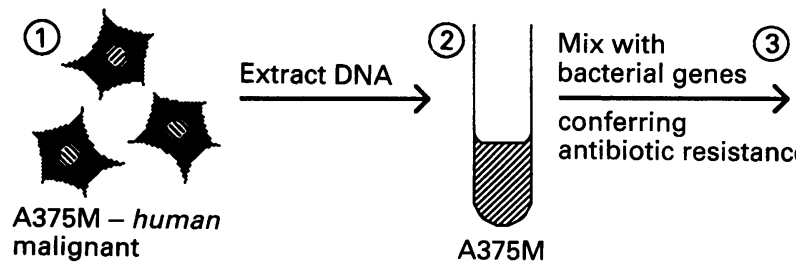

malignant

melanoma cell line, highly metastatic in nude mice

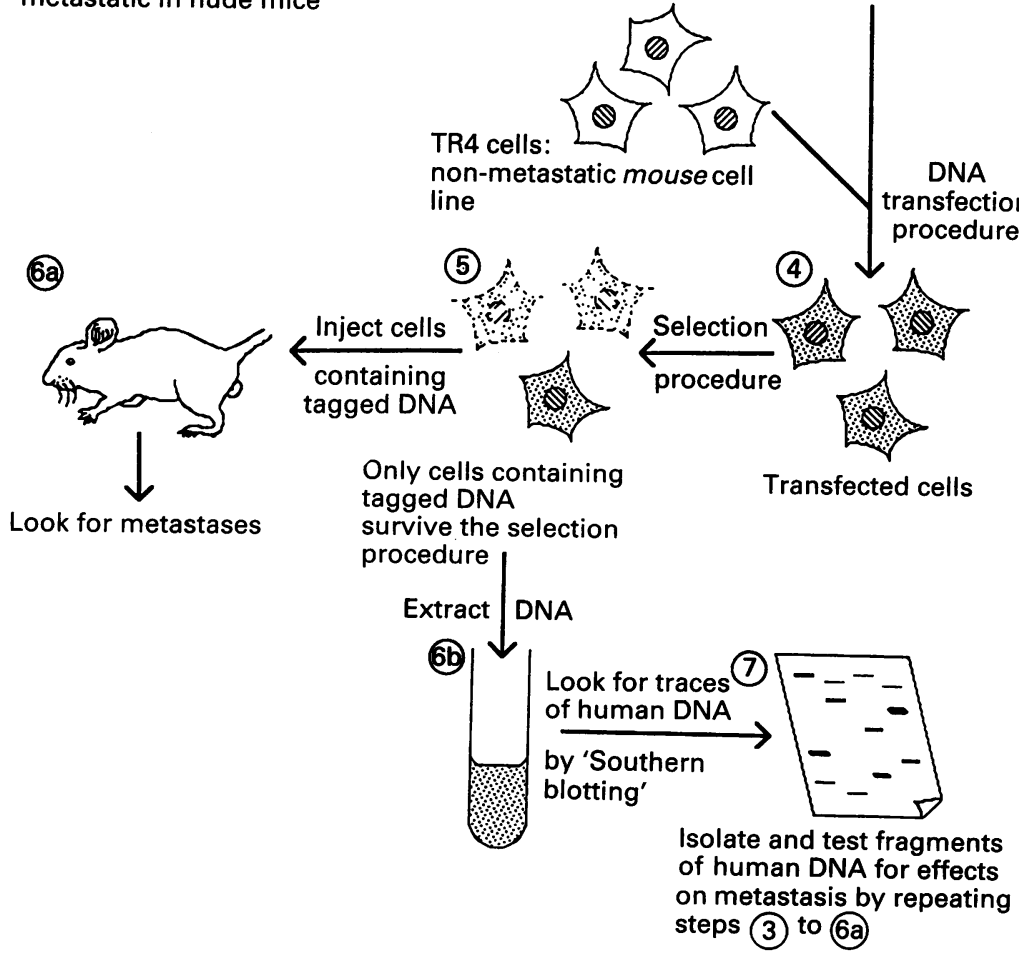

Figure 4 Experimental protocol for transfection of metastasis. fecting total genomic DNA from a human malignant melanoma cell line into a nonmetastatic mouse tumour cell line. ${ }^{7}$ The plan of experiment is summarised in fig 4 . Secondary transfer of this property was also achieved in a second round of DNA transfection into fresh cells of the same non-metastatic mouse line. The DNA used for this second transfer was obtained from a cell line derived from a pulmonary metastasis made by the primary transfectants. Concomitant transfer of human DNA through both transfection cycles has been shown by several methods, including probing Southern blots with probes for human specific Alu repeat sequences, in situ hybridisation, and Alu PCR. Finally, a portion of the transfected human DNA was recovered by screening a genomic library made from the transfected metastatic cells. This has been sequenced and is a 2858 base pair fragment containing previously unrecorded human coding regions. Using PCR primers we designed to one of these, in an RT-PCR analysis of mRNA extracted from fresh human tumours and normal tissues, we have seen marked differences in the expression of this sequence in malignant tumours, relative to benign tumours and normal tissues. More samples are being examined but the results to date clearly indicate that the probe distinguishes tumour tissue with metastatic potential and that it could therefore be useful in clinical practice.

In 1988 Steeg and colleagues cloned and sequenced a separate gene which seems to be relevant to the metastatic process and may have diagnostic potential. ${ }^{25}$ This gene, designated nm23, was isolated by differential hybridisation from a non-metastatic mouse cell line and is conserved in human cells. Studies to date show a promising correlation between reduced expression of the gene and metastasis in patients with breast cancer, ${ }^{26}{ }^{27}$ but the results in colon carcinoma have been contradictory. ${ }^{28}{ }^{29}$ The gene might prove to be a useful marker and further results are awaited with interest.

Very recently results from three laboratories $^{30-32}$ have indicated that counting the number of capillaries in the most vascularised area of a tumour might give a useful pragmatic indication of patient survival or of tumour recurrence in breast cancer and non-small cell lung cancer. The underlying basis for this clinical evaluation is the well established knowledge that vascularisation is essential for tumours to grow beyond a few millimetres in size, and for dissemination of tumours by blood and lymphatic routes. Although there is very good statistical correlation between vessel density in histological sections and prognosis, it remains to be seen in further studies whether it is a useful index for the evaluation of individual patients.

\section{Invasion}

Once tumour cells have activated internal genetic mechanisms for dissemination from the expanding primary lesion, they radiate outwards into the surrounding tissue releasing proteases, especially collagenases ${ }^{33} 34$ (fig 5) and destroying much of the extracellular 
matrix which they encounter ${ }^{35-37}$ (fig 6) until they collide with local capillary blood vessels and lymphatics. The former are sheathed in basement membranes which are not readily breeched by most normal cells. However, they have to be traversed by tumour cells programmed to disseminate by entering vascular channels, or by patrolling lymphocytes passing through the tissues on routine surveillance missions.

These membranes contain laminin and collagen type IV and the latter is selectively digested by a specific metalloprotease, gelatinase, otherwise known as collagenase IV, which is reported to be secreted in increased quantities by several types of tumour cells. It has also been suggested that this enzyme is secreted in greater quantity by cell lines which are highly metastatic than by ones which are not. ${ }^{38}$ There is little doubt now that both this and collagenase $\mathrm{I}$, which selectively digests collagen I, the main structural component of the extracellular mesenchyme, are active in tumour invasion and metastasis. Even so, the production of these lytic agents in tumours is spatially and temporally erratic, and there is no direct evidence that collagenase values of individual lesions are of diagnostic or prognostic value in clinical oncological practice. With the recent advent of new, collagenase specific inhibiting drugs, which remain active after absorption via the oral route, however, the possibility of reducing local tissue destruction or delaying distant metastasis has appeared on the horizon. Long term trials will be needed to evaluate such agents, not only to assess whether they are effective, but also because of the need to ensure that they have no detrimental effects on collagen metabolism

Figure 5 Polyacrylamide gel electrophoresis of digestion products (arrows) of type 1 collagen exposed to culture supernatant fluids, from human breast carcinomas (tracks 2 and 4 numbering from left).

Digestion was inhibited by addition of EDTA (tracks 3 and 5) confirming it was due to a specific mammalian metalloprotease-namely, collagenase. Track1 undigested collagen control track 6 molecular weight markers.

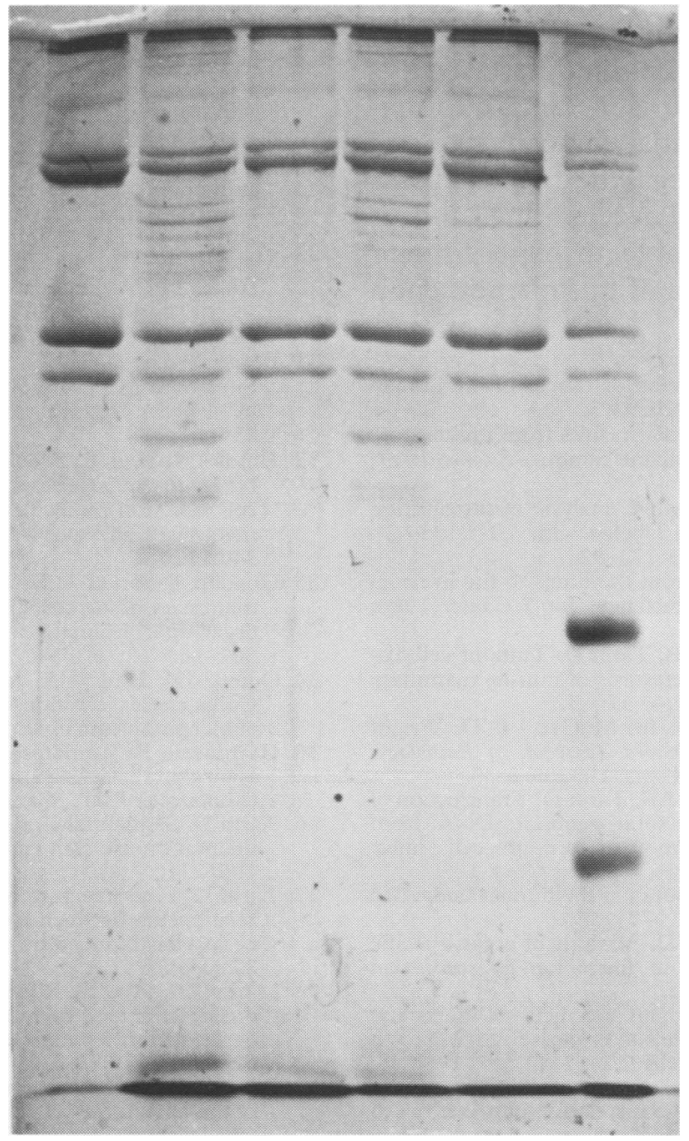

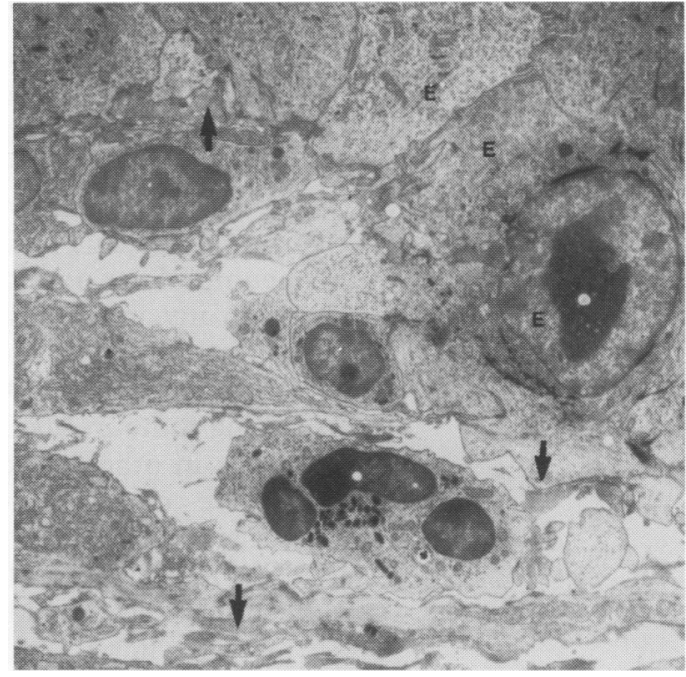

Figure 6 Electron micrograph of the advancing edge of a deeply invasive skin carcinoma showing extensive disorganisation of connective tissue extending several microns in advance of the neoplastic epithelium (E) which is extending clear pseudopodia into the vacant space created by lysis of adjacent tissue. There are few remaining collagen fibres (arrows) and the basement membrane has been demolished.

and turn-over in the normal tissues and organs of the host. Potentially, such agents could be effective against local invasion and metastasis from the primary tumour as well as in impeding similar activities of secondary deposits.

\section{Tumour cell dissemination and patterns of metastasis}

Over a century ago Stephen Paget realised that the distribution of metastases from such tumours is not random. He inferred that the process depended both on intrinsic properties of the disseminating tumour cells and of the organ in which they became detained after being scattered. This work gave rise to the "seed and soil" hypothesis of metastasis. ${ }^{39}$ Actually this deduction was a formidable achievement, based on remarkably clear, direct, and independent thinking, especially if one remembers that the bulk of the pathological establishment at that time, including Virchow, were in dispute about whether tumour metastasis resulted from dissemination of cancer cells or of infective agents released by the tumour.

Although this controversy was soon settled, direct confirmation of the hypothesis had to await experiments with cultured tumour cell lines in inbred syngeneic strains of animals and in nude mice. Final confirmation in humans took still longer and was only obtained through a fortuitous opportunity provided by the introduction of a novel form of palliative treatment for patients with intractable ascites caused by inoperable abdominal malignancy. ${ }^{12}$ The technique of peritoneo-venous shunting is sometimes used to relieve pain and discomfort in patients with recurrent malignant ascites. These patients go into severe metabolic imbalance if large volumes of such fluid, and its constituent nutrients and metabolites, are regularly removed by the simpler procedure of paracentesis. The shunt resolves the metabolic problem by 
returning the fluid to the circulation via the jugular vein, but simultaneously infuses billions of viable tumour cells, floating in the ascites, directly into the blood for protracted periods of time. Amazingly, some patients whose ascitic cells were undoubtedly viable and tumourigenic on implantation in the peritoneum did not develop any detectable metastases in any organ, despite surviving for up to 2 years before dying from local tumour burden in the original site. Other patients developed seedling tumours via the shunt in some organs but not in others, and the organ distribution of these corresponded to that of known metastases before the shunt was inserted.

The implications of these findings are that:

- tumour cell shedding into the blood does not inevitably result in metastasis;

- there is massive redundancy (cell destruction) and selectivity caused by stochastic (chance) factors in the process;

- tumour cell populations which are incontestably metastatic can still colonise only certain sites, as Paget predicted.

Clinically this information is useful because it provides hope for both physician and patient that the entry of tumour cells into the circulation-for example during surgery, does not inevitably spell doom. It also endorses that knowledge of the patterns of metastatic spread of various tumours is useful for selecting protocols for monitoring recurrence, and it suggests possible new avenues worth exploring for treatment. Subsequent additional work showed that soluble organ specific factors may influence metastatic colonisation ${ }^{9-11}$ and raised the idea that purification and identication of the natural agents which can inhibit formation of metastasis could provide a novel, natural, and possibly non-toxic, form of treatment for established metastatic disease.

The above brief summary indicates that research on tumour invasion and metastasis is becoming very active and is yielding information that is both of potential clinical value and of help for unravelling the mechanisms involved. The pace is accelerating and it would not be unreasonable to expect major advances towards control of this phenomenon in the next few years.

1 Darling D, Tarin D. The spread of cancer in the human body. New Scientist 1990;1726:50-3.

2 Fidler IJ, Kripke ML. Metastasis results from pre-existing variant cells within a malignant tumour. Science 1977 197:893-5.

3 Fidler IJ. Metastasis: quantitative analysis of distribution and fate of tumour emboli labeled with 125I-5-Iodo-2' deoxyuridine. $\{N C I$ 1970;45:773-82.

4 Weiss L. Cancer cell traffic from the lungs to the liver: an example of metastatic inefficiency. Int $f$ Cancer 1980; 25:385-92.

5 Juacaba SF, Horak E, Price JE, Tarin D. Tumour cell dissemination patterns and metastasis of murine mammary semination patterns and metastasis of
carcinoma. Cancer Res 1989;49:570-5.

6 Tarin D. Tumour metastasis. In: McGee J O'D, Wright NA, Isaacson PG, eds. Oxford Textbook of Pathology. Oxford: Oxford University Press, 1992:607-33.

7 Hayle AJ, Darling DL, Taylor AR, Tarin D. Transfection of metastatic capability with total genomic DNA from metastatic human and mouse tumour cell lines. Differentiation 1993;54:18

8 Willis RA. The spread of tumours in the human body. 3rd edn. London: Butterworth 1973.

9 Horak E, Darling DL, Tarin D. Analysis of organ-specific effects on metastatic tumour formation by studies in vitro. FNCI 1986;76:913-22.

10 Nicolson GL, Dulski KM. Organ specificity of metastatic tumour colonization is related to organ-selective growth properties of malignant cells. Int $\mathcal{f}$ Cancer 1986;38: 289-94.

11 Naito S, Giavazzi R, Fidler IJ. Correlation between the in vitro interactions of tumour cells with an organ microenvironment and metastasis in vivo. Invasion Metastasis 1987;7:126-9.

12 Tarin D, Price JE, Kettlewell MGW, Souter RG, Vass ACR, Crossley B. Mechanisms of human tumour metastasis studied in patients with peritoneovenous shunts. Cancer Res 1984;44:3584-92.

13 Matsumura Y, Tarin D. Significance of CD44 gene products for cancer diagnosis and disease evaluation. Lancet 1992;340:1053-8.

14 Tanabe KK, Ellis LM, Saya H. Expression of CD44R1 adhesion molecule in colon carcinomas and metastases. Lancet 1993;341:725-6.

15 Finn L, Becich M, Dougherty G, Finley G, Meisler A, Cooper D. CD44 alternative splicing in human colon carcinomas. Lab Invest 1993;68:49A

16 Heider K-H, Hofmann M, Hors E, van den Berg F, Ponta $\mathrm{H}$, Herrlich P, Pals ST. A human homologue of the rat metastasis-associated variant of CD44 is expressed in colorectal carcinomas and adenomatous polyps. $¥ \mathrm{Cell}$ Biol 1993;120:227-33.

17 Haynes BF, Telen MJ, Hale LP, Denning SM. CD44-A molecule involved in leukocyte adherence and $\mathrm{T}$-cell molecule involved in leukocyte adherence

18 Matsumura $Y$, Hanbury $D$, Smith J, Tarin D. Non-invasive detection of malignancy by identification of unusual CD44 gene activity in exfoliated cancer cells. $\mathrm{Br}$ Med $\mathcal{F}$ 1994;308:619-23.

19 Tarin D. Clinical and experimental studies on the biology of metastasis. Biochim Biophys Acta 1985;780:227-35.

20 Bao L, Pigott R, Matsumura Y, Baban D, Tarin D Correlation of VLA-4 integrin expression with metastatic potential in various human tumour cell lines. Differentiation 1993;52:239-46.

21 Gunthert U, Hofmann M, Rudy W, Reber S, Zoller M Haubmann I, et al. A new variant of glycoprotein CD44 confers metastatic potential to rat carcinoma cells. Cell confers metastatic

22 Sidransky D, Eschenbach AV, Tsai YC, Jones $P$ Summerhayes I, Marshall F, et al. Identification of p53 gene mutations in bladder cancers and urine samples. Science 1991;252:706-9.

23 Halliassos A, Liloglou T, Likourinas M, Doumas C, Ricci $\mathrm{N}$, Spandidos DA. H-ras oncogene mutations in the urine of patients with bladder tumors: description of a non-invasive method for the detection of neoplasia. Int $\mathcal{f}$ Oncol 1992;1:731-4.

24 Nguyen $M$, Watanabe $H$, Budson AE, Richie JP, Folkman J. Elevated levels of the angiogenic peptide basic fibroblas growth factor in urine of bladder cancer patients. FNCI growth factor in

25 Steeg PS, Bevilacqua G, Kopper L, Thorgeirsson UP, Talmadge JE, Liotta LA, et al. Evidence for a novel gene associated with low tumour metastatic. potential. भNC 1988;80:200-4.

26 Barnes R, Masood S, Barker E Rasengard AM, Coggin $\mathrm{DL}$, Crowell $\mathrm{T}$, et al. Low nm23 protein expression in reduced patient survival. Am $₹$ Pathol 1991;139:245-50.

27 Hennessy C, Henry JA, May FEB, Westley BR, Angus B, Lennard TWJ. Expression of the antimetastatic gene nm23 in human breast cancer: an association with good nm23 in human breast cancer:

28 Cohn KH, Wang F, Desoto-Lapaix F, Solomon WB, Patterson LG, Arnold MR, et al. Association of nm23$\mathrm{H} 1$ allelic deletions with distant metastases in colorecta carcinoma. Lancet 1991;338:722-4.

29 Haunt M, Steeg PS, Willson JKV, Markowitz SD Induction of nm23 gene expression in human colonic neoplasms and equal expression in colon tumors of high and low metastatic potential. ҰNCI 1991;83:712-6.

30 Macchiarini P, Gontanini G, Hardin MJ, Squartini F Angeletti CA. Relation of neovascularisation to metastaAngeletti CA. Relation of neovascularisation to metasta-
sis of non-small-cell lung cancer. Lancet 1992;340: sis of

31 Bosari S, Lee AK, DeLellis RA, Wiley BD, Heatley GJ, Silverman ML. Microvessel quantitation and prognosis in invasive breast carcinoma. Hum Pathol 1992;23. 755-61.

32 Horak ER, Leek R, Klenk N, Le-Jeune S, Smith K, Stuar $\mathrm{N}$, et al. Angiogenesis, assessed by platelet/endothelia cell adhesion molecule antibodies, as indicator of node metastases and survival in breast cancer. Lancet 1992, 340:1120-4.

33 Hossain A, Sarkar A, Sarkar NH. Mixed inocula of mouse mammary tissue cell subpopulations result in changes in organ-specific metastasis. Invasion Metastasis 1991;9: organ-specir

34 Ogilvie DJ, Hailey JA, Juacaba SF, Lee ECG, Tarin D. Collagenase secretion by human breast neoplasms: A Collagenase secretion by human breast neoplasms:

35 Hashimoto K, Yamanishi Y, Maeyens E, Dabbous MK Kanzaki T. Collagenolytic activities of squamous-cel carcinoma of skin. Cancer Res 1973;33:2790-801.

36 Tarin D. Sequential electron microscopical study of experimental mouse skin carcinogenesis. Int $\mathcal{F}$ Cancer 1967;2 195-211.

37 Tarin D. Fine structure of murine mammary tumours: the relationship between epithelium and connective tissue in neoplasms induced by various agents. Br F Cancer 1969 23:417-25.

38 Liotta LA, Abe S, Robey PG, Martin GR. Preferential digestion of basement membrane collagen by an enzym derived from a metastatic murine tumor. Proc Natl Acad Sci USA 1979;76:2268-72.

39 Paget S. The distribution of secondary growths in cance of the breast. Lancet 1889;1:571-3. 